\title{
Methods for calculating the reinforcement of concrete slabs with carbon composite materials based on the finite element model
}

\author{
Valeriy Telichenko, Vladimir Rimshin ${ }^{*}$ and Ekaterina Kuzina \\ Moscow State University of Civil Engineering, Yaroslavskoe shosse, 26, Moscow, 129337, Russia
}

\begin{abstract}
In this article, a method is proposed for calculating the reinforcement of concrete ceiling slabs with carbon composite materials based on the finite element model in the computer program SCAD Office PC. This method allows the most complete and accurate representation to be obtained of the structure stress-strain state before and after reinforcement with composite materials. Therefore, it allows high-quality designing and reduces the cost conducting calculations and tests on a large scale. The design values are taken from the initial data, and include conclusions based on the results of analysis of the technical state of the structures and drawings from the calculation section of the CS (reinforced concrete structures).
\end{abstract}

\section{Introduction}

Nowadays, both Russian and foreign researchers pay considerable attention to the problem of ensuring the reliability of building structures at all stages of their construction and maintenance, especially in the case of their repair and strengthening [1-3]. This is due to the growing need to ensure reliable operation of unique, expensive and- historically significant structures, the dismantling and replacement of which is much more expensive than repair or completely impossible. Reinforced concrete structures damages, as a rule, are associated with corrosion, the overloading of separate elements and improper operation, as well as design and production errors. Strengthening of building structures with composite materials is by far the most "careful" method of restoring and improving the operational characteristics of building structures [4-7].

The most common solution for strengthening reinforced concrete structures with the use of carbon fiber is the location of the external reinforcement element from the side of the most stretched fiber in the span of bent structures, although there has been a successful attempt of strengthening the compressed zone. Both tapes and canvases can be installed in the area of the fly-by moments. Recently there has been a trend of wide use of canvases.

\footnotetext{
Corresponding author: v.rimshin@ niisf.ru
} 
This is due to their higher mechanical characteristics, simplicity of installation and reliability of anchoring $[8,10]$.

An important area of applying external reinforcement elements is strengthening pricked sections in the shear forces action zone. In these zones, as a rule, coal coils are located along the line of principal tensile stresses [9]. They can be glued in several layers and form any sections needed for calculation.

\section{Materials and methods}

The design values are taken from the initial data, and include a technical conclusion based on the analysis results of the technical state of the structures and drawings from the calculation section of the CS project (reinforced concrete structures).In the calculation, the slab is considered at $-8,100$.

The thickness of the slab is $300 \mathrm{~mm}$. In the technical conclusion, based on the results of the analysis the minimum class of concrete for durability in compression isB22,5. Because there is no this class in Norms, the concrete strength class- B20 is adopted. The reinforcement of the lower zones of the slab section is taken from the technical conclusions from the analysis:

- Along letter axes - $\emptyset 16 \mathrm{~A} 400$ step $245 \mathrm{~mm}\left(\mathrm{As}=2,011 \times 4=8,044 \mathrm{~cm}^{2}\right)$;

- Along the numerical axes - $\varnothing 16 \mathrm{~A} 400 \mathrm{step} 240 \mathrm{~mm}\left(\mathrm{As}=2,011 \times 4=8,044 \mathrm{~cm}^{2}\right)$.

The protective layer is $45 \mathrm{~mm}$ (the bottom is the reinforcement along the letter axes).

\section{Loads}

The load from the weight of the partitions is calculated taken from Norms. The temporary load was calculated taken from the technical conclusion.

Because there are no data on the actual structures of the floors, the explication of the premises or the presence and location of equipment in the original documentation of the architectural section, the uniformly distributed loads in Table 1 are taken into account.

Table 1. Loads on slab

\begin{tabular}{|c|c|c|c|c|c|c|}
\hline No & $\begin{array}{l}\text { Construction } \\
\text { element }\end{array}$ & $\begin{array}{c}\text { Specific } \\
\text { gravity, } \mathrm{t} / \\
\mathrm{m}^{3}\end{array}$ & $\begin{array}{c}\text { Layer } \\
\text { thickness, } \\
\text { m }\end{array}$ & $\begin{array}{c}\text { Specified } \\
\text { characteristic } \\
\text { load, } \mathrm{t} / \mathrm{m}^{3}\end{array}$ & $\begin{array}{c}\text { Partial } \\
\text { safety factor } \\
\gamma_{\mathrm{f}}\end{array}$ & $\begin{array}{l}\text { Calculated } \\
\text { load, } t / \mathrm{m}^{3}\end{array}$ \\
\hline \multicolumn{7}{|c|}{ Constant } \\
\hline 1 & $\begin{array}{l}\text { In-situ concrete } \\
\text { slab }\end{array}$ & 2.5 & 0.3 & 0.75 & 1.1 & 0.825 \\
\hline 2 & $\begin{array}{l}\text { Leveling screed } \\
(20-110 \mathrm{~mm}) *\end{array}$ & 1.8 & 0.11 & 0.198 & 1.3 & 0.257 \\
\hline 3 & Concrete footing & 1.8 & 0.07 & 0.126 & 1.3 & 0.164 \\
\hline 4 & Partition weight & - & - & 0.05 & 1.3 & 0.065 \\
\hline \multicolumn{4}{|c|}{ TOTAL: } & 1.124 & & 1.311 \\
\hline \multicolumn{7}{|c|}{ Temporary } \\
\hline 5 & \multicolumn{3}{|c|}{ Loads for subterranean parking } & 0.35 & 1.2 & 0.42 \\
\hline & \multicolumn{3}{|c|}{ In all (Constant+ Temporary): } & 1.434 & & 1.731 \\
\hline
\end{tabular}

* - to compensate for excessive deflection of slab area. 


\section{Results and discussion}

The model is calculated by means SCAD Office 11.5 software. To more accurately determine the stress-strain state of the modeling slab, a calculation section of the slab was taken, which exceeds the area considered (requiring repair and reinforcement) by two column spacing on both sides [11-12]. The slab model is shown in Figure 1.

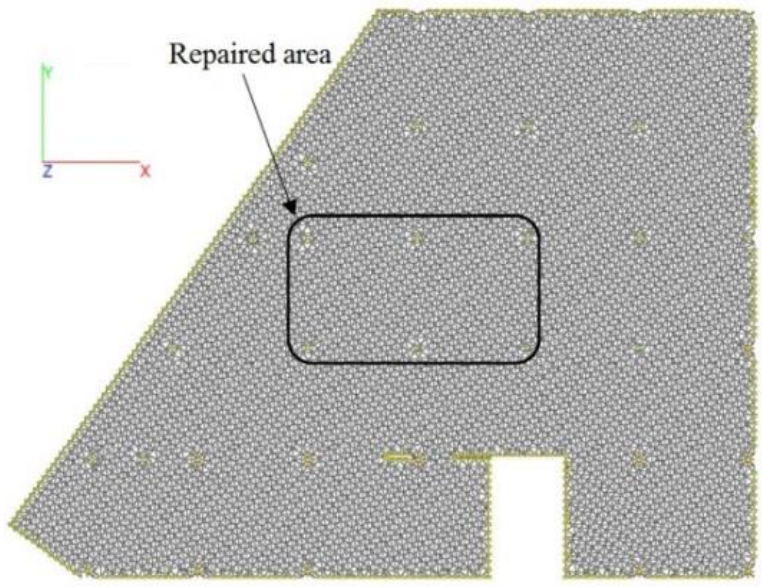

Fig. 1. Finite element model

The isopoles of the calculated bending moments $\mathrm{M}_{\mathrm{x}}$ and $\mathrm{M}_{\mathrm{y}}$ are shown in Figures 2 and 3, respectively. The maximum bending moments in the section of the overlap plate for the different calculation stages are shown in Table 2.

\section{Determination internal efforts and deficit limits}

The calculation was carried out for the first limiting state in order to determine the carrying capacity. The limiting internal forces are determined by the deformation model of reinforced concrete in accordance with the instructions Norms. The calculated diagram of the compressed concrete state is assumed to be trilinear [9].

\begin{tabular}{|c|c|c|}
\hline $4 \square$ & $-26,42$ & -24.0 \\
\hline$\vee \square$ & $-24,0$ & -21.58 \\
\hline $8 \square$ & .21 .58 & $-19,16$ \\
\hline$x \square$ & $-19,16$ & $-16,74$ \\
\hline$\checkmark \square$ & $-16,74$ & $-14,31$ \\
\hline$\vee \square$ & $-14,31$ & $-11,89$ \\
\hline$v \square$ & $.11,89$ & $-9,47$ \\
\hline$\vee \square$ & $-9,47$ & -7.05 \\
\hline$x \square$ & .7 .05 & 4.63 \\
\hline $18 \square$ & -4.63 & -2.21 \\
\hline$\checkmark \square$ & -2.21 & 0.21 \\
\hline $8 \square$ & 0.21 & 2.64 \\
\hline$\forall \square$ & 2,64 & 5.06 \\
\hline$x \square$ & 5,06 & 7.48 \\
\hline
\end{tabular}

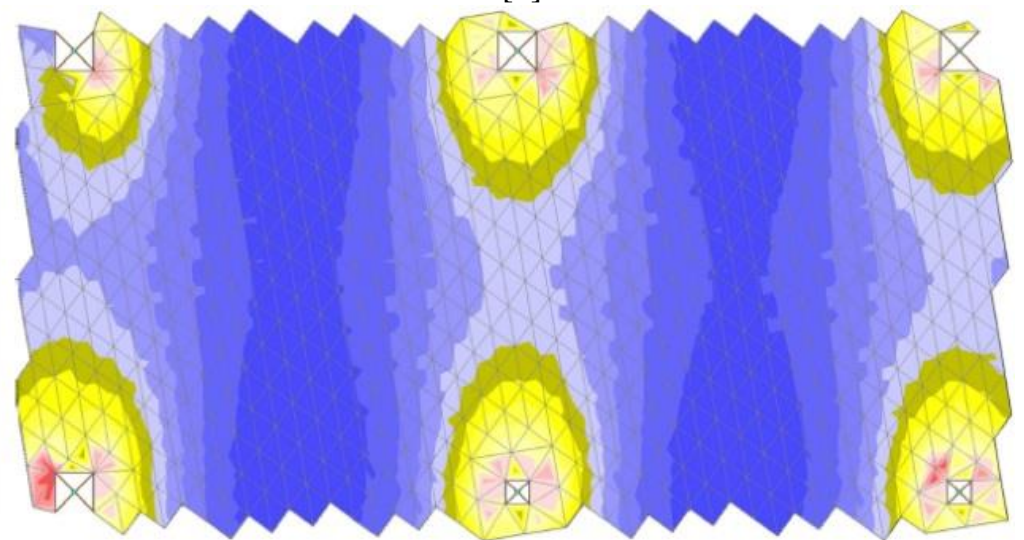

Fig.2. Isopole of bending moments $\mathrm{M}_{\mathrm{x}}$ 


\begin{tabular}{|c|c|c|}
\hline$\nabla \square$ & -26.67 & $.24,19$ \\
\hline$\underline{\nabla} \square$ & $-24,19$ & .21 .7 \\
\hline$\underline{\nabla} \square$ & .217 & -19.22 \\
\hline$\underline{\square \square}$ & -19.22 & $-16,73$ \\
\hline$x \square$ & $-16,73$ & -14.25 \\
\hline$\underline{\square} \square$ & $-14,25$ & -11.76 \\
\hline$x \square$ & -11.76 & .928 \\
\hline$\forall \square$ & $-9,28$ & $-6,79$ \\
\hline$\underline{\square} \square$ & $-6,79$ & $-4,31$ \\
\hline$\underline{\square} \square$ & -431 & -1.83 \\
\hline$x \square$ & -1.83 & 0.66 \\
\hline$\forall[$ & 0.66 & 3,14 \\
\hline$\forall \square$ & 3.14 & 5.63 \\
\hline$\underline{Z L} \square$ & 5.63 & 8.11 \\
\hline
\end{tabular}

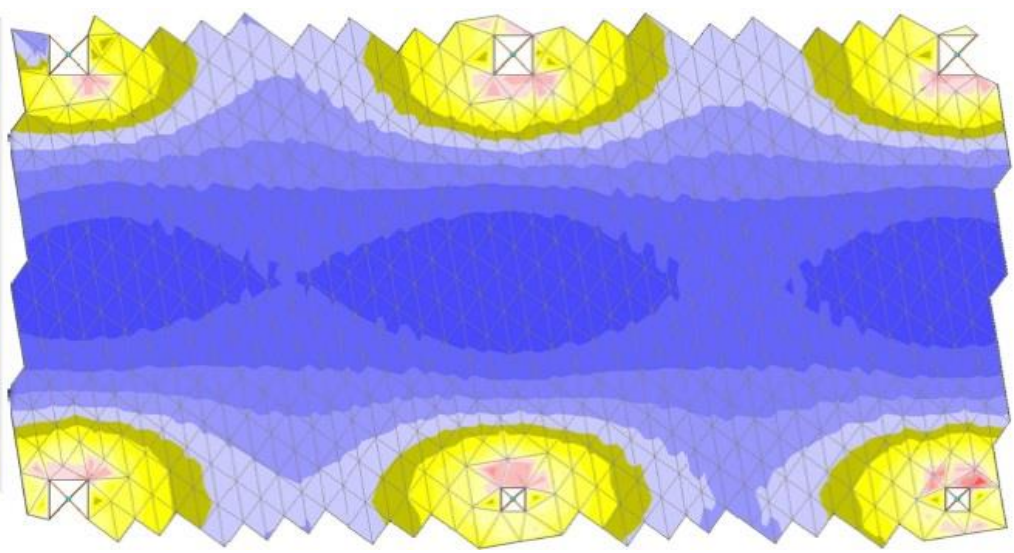

Fig. 3. Isopole of bending moments $\mathrm{M}_{\mathrm{y}}$

Table 2. Standard and calculated values of internal forces in lower (transit) zone of slab section

\begin{tabular}{|c|l|c|c|}
\hline No. & \multicolumn{1}{|c|}{ Value } & $\mathrm{M}_{\mathrm{x}}, \mathrm{t} / \mathrm{m}$ & $\mathrm{M}_{\mathrm{v}}, \mathrm{t} / \mathrm{m}$ \\
\hline & Non reinforced construction & 6.3 & 6.82 \\
\hline 1 & Standard value & 7.48 & 8.11 \\
\hline 2 & Calculated value & 2.85 & 2.95 \\
\hline & Non reinforced construction at the moment of enforcement \\
\hline 3 & Regulation value & 3.13 & 3.24 \\
\hline 4 & Calculated value &
\end{tabular}

* - only weight of reinforced concrete slab is taken into account.

Determining $\mathbf{M}_{\mathbf{x}}$, ult

The limiting value of the bending moment is given in Table 3 .

Table 2.1.Stresses, Units: kN, cm

\begin{tabular}{|c|c|c|}
\hline Parameter & Value & Coefficient \\
\hline$\sigma_{b, \max }$ & -0.75 & 0.65 \\
\hline$\sigma_{s, 1}$ & 35.5 & 1 \\
\hline
\end{tabular}

Table 2.2. Occupation coefficient (deformation)

\begin{tabular}{|l|c|}
\hline Compressed concrete & 0.1364 \\
\hline Tensile reinforcement & 0.9999 \\
\hline Reinforcement material & - \\
\hline
\end{tabular}

\section{Stress pattern in cross-section}

$$
\xi=\frac{5,31}{30-5,3}=0,218 \leq \xi_{R}=\frac{0,8}{30+\frac{0,001775}{0,0035}}=0,53
$$

Determining $\mathbf{M}_{\mathbf{y}}$, ult

The limiting value of the bending moment is given in Table 3. 


$$
\xi=\frac{5,38}{30-6,1}=0,225 \leq \xi_{R}=\frac{0,8}{30-\frac{0,001775}{0,0035}}=0,53
$$

Table 2.3.Stresses, Units: $\mathrm{kN}, \mathrm{cm}$

\begin{tabular}{|c|c|c|}
\hline Parameter & Value & Coefficient \\
\hline$\sigma_{b, \max }$ & -0.754 & 0.66 \\
\hline$\sigma_{s, 1}$ & 35.5 & 1 \\
\hline
\end{tabular}

Table 2.4. Occupation coefficient (deformation)

\begin{tabular}{|l|c|}
\hline Compressed concrete & 0.1401 \\
\hline Tensile reinforcement & 1 \\
\hline Reinforcement material & - \\
\hline
\end{tabular}

\section{Stress pattern in cross-section}

\section{Determining bearing capacity deficits}

The limit values of the internal forces and carrier deficits of the bearing capacity are shown in Table 3.

Table 3. Deficits of the bearing capacity

\begin{tabular}{|l|l|c|c|}
\hline No. & \multicolumn{1}{|c|}{ Type of value } & $\mathrm{M}_{\mathrm{x}}, \mathrm{t} / \mathrm{m}$ & $\mathrm{M}_{\mathrm{y}}, \mathrm{t} / \mathrm{m}$ \\
\hline 1 & Current value & 7.48 & 8.11 \\
\hline 2 & Limiting value & 6.58 & 6.36 \\
\hline & Deficits, $\%$ & 13.7 & 27.5 \\
\hline
\end{tabular}

\section{Calculation of reinforced slab}

The carbon tape FibArm 530/300 is used as the material for the reinforcing elements.

The standard composite design resistance: $R_{f, n}=1100 \mathrm{MPa}$. The limiting bending moments and the crack opening in the reinforced section are determined by the deformation model of reinforced concrete in accordance with the instructions in Norms. The calculated diagram of the state of compressed concrete is assumed to be trilinear [9]. The efforts in the section at the time of strengthening work are indicated in Table 2.

\section{Calculating reinforced slab portion according to first limit state}

The calculated value of resistance of the first layer of the composite is:

$$
R_{\mathrm{f}}=320.7 \mathrm{MPa} \text {. }
$$

The width of the composite is $300 \mathrm{~mm} / \mathrm{m}$; the thickness is $1 \mathrm{~mm}$. The composite area is: $A_{\mathrm{f}}=3 \mathrm{~cm} / \mathrm{m}^{2}$.

Determining $M_{x}$, ult and $M_{y}$, ult

The results of calculating the stress-strain state are shown in Figure 4. The limiting value of the bending moment is given in Table 4.

For $\mathrm{M}_{\mathrm{x}, \text { ult }}$ :

$$
\xi=\frac{5,51}{30}=0,184 \leq \xi_{R}=\frac{0,8}{30+\frac{0,00465+0,00103}{0,0035}}=0,305
$$

For $\mathrm{M}_{\mathrm{y} \text {, ult }}$ : 


$$
\xi=\frac{5,51}{30}=0,184 \leq \xi_{R}=\frac{0,8}{30+\frac{0,00465+0,00116}{0,0035}}=0,301
$$

Table 3.1. Stresses, Units: $\mathrm{kN}$, cm

\begin{tabular}{|l|c|c|}
\hline Parameter & Value & Coefficient \\
\hline$\sigma_{b, \max }$ & -0.95 & 0.83 \\
\hline$\sigma_{s, 1}$ & 35.5 & 1 \\
\hline$\sigma_{f}$ & 32.07 & 1 \\
\hline
\end{tabular}

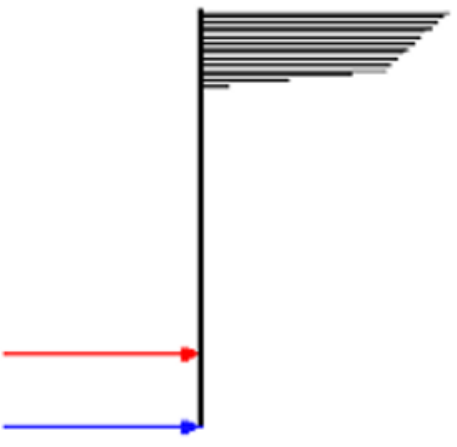

Height of compression zone $\mathrm{x}=5,51 \mathrm{~cm}$

Fig.4.Calculation results $M_{x, \text { ult }}$ and $M_{y, u l t}$

Table 3.2. Deformations

\begin{tabular}{|c|c|c|}
\hline Parameter & Value & Coefficient \\
\hline$\varepsilon_{b, \max }$ & -0.00124 & 0.35 \\
\hline$\varepsilon_{s, 1}$ & 0.00446 & 2.51 \\
\hline$\varepsilon_{f}$ & 0.00465 & 1 \\
\hline
\end{tabular}

Table 3.3. Stresses. Units: kN, cm

\begin{tabular}{|c|c|c|}
\hline Parameter & Value & Coefficient \\
\hline$\sigma_{b, \max }$ & -0.96 & 0.83 \\
\hline$\sigma_{s, 1}$ & 35.5 & 1 \\
\hline$\sigma_{f}$ & 32.07 & 1 \\
\hline
\end{tabular}

Table 3.4. Deformations

\begin{tabular}{|l|c|c|}
\hline Parameter & Value & Coefficient \\
\hline$\varepsilon_{b, \max }$ & -0.00127 & 0.36 \\
\hline$\varepsilon_{s, 1}$ & 0.00437 & 2.46 \\
\hline$\varepsilon_{f}$ & 0.00465 & 1 \\
\hline
\end{tabular}


The limit values of internal forces and load-bearing capacity are shown in Table 4.

Table 4. Reserves of bearing capacity

\begin{tabular}{|l|l|c|c|}
\hline No. & \multicolumn{1}{|c|}{ Type of value } & $\mathrm{M}_{\mathrm{x}}, \mathrm{t} / \mathrm{m}$ & $\mathrm{M}_{\mathrm{y}}, \mathrm{t} / \mathrm{m}$ \\
\hline 1 & Current value & 7.48 & 8.11 \\
\hline 2 & Limiting value & 9.83 & 9.67 \\
\hline & Reserve, \% & 31.4 & 19.2 \\
\hline
\end{tabular}

Calculation of the crack opening width with the selected gain is performed. The calculated value of resistance of the first composite layer is:

$$
R_{f}=366,2 M P a
$$

Table 5. Reserves for crack resistance*

\begin{tabular}{|l|l|c|c|}
\hline No. & Type of value & Crack width from $\mathrm{M}_{\mathrm{x}}, \mathrm{mm}$ & Crack width from $\mathrm{M}_{\mathrm{y}}, \mathrm{mm}$ \\
\hline 1 & Current value & 0.201 & 0.24 \\
\hline 2 & Limiting value & 0.3 & 0.3 \\
\hline & Reserve, $\%$ & 33 & 20 \\
\hline
\end{tabular}

* Note: crack width is calculated using design values of bending moments from Table 2.

\section{Conclusions}

The method of reinforced calculating concrete structures (overlapping slabs) al-lows one to obtain a more accurate picture of the stress-strain state in the structure before strengthening and after it, in contrast to traditional manual calculation [13]. Based on the results of the calculation, it is possible to select a more adequate strengthening scheme - by changing the geometry or stiffness characteristics of the carbon fiber reinforced polymer (CFRP). It is shown that applying of the calculation technique allows one to improve the quality of the reinforcement design of concrete slabs, to reduce the costs of carrying out experimental design work and full-scale testing.

\section{References}

1. V.M. Bondarenko, V.I. Rimshin, Dissipative Theory of Strength Resistance of Reinforced Concrete Moscow, (2015)

2. V.M. Bondarenko, V.I. Rimshin, Herald of the Department of Building Sciences of the Russian Academy of Architecture and Building Sciences. No. 9. P. 119. (2005)

3. V.L. Kurbatov Practical manual of the civil engineer, Moscow, (2012)

4. V.L. Kurbatov, V.I. Rimshin, Shumilova E.Yu. Construction and technical expertise of Mineral Waters, (2015)

5. Larionov E.A., V.I. Rimshin, N.T. Vasilkova Construction mechanics of engineering structures and structures. No. 2. P. 77-81. (2012)

6. V.I. Rimshin, V.A. Gredzhev Fundamentals of legal regulation of urban development. (2nd edition, revised and enlarged) Moscow, (2015)

7. V.I. Rimshin, V.A. Gredzhev Ser. Textbook XXI century. Bachelor. Moscow, (2015)

8. V.I. Rimshin, V.A. Gredzhev Legal regulation of urban activities and housing legislation. Moscow, (2013). (2nd edition)

9. V. T. Erofeev, E. V. Zavalishin, V.I. Rimshin, V. L. Kurbatov, B. S. Mosakov Research Gournal of Pharmaceutical, Biological and Chemical Sciences. V.7. No. 3.P. 2506-2517. (2016) 
10. S.A. Korotaev, V.I. Kalashnikov, V.I. Rimshin, I.V. Erofeeva, V.L. Kurbatov Ecology, Environment and Conservation. V. 22. No. 3. P. 1159-1164.

11. V.T. Erofeev, A.D. Bogatov, S.N. Bogatova, V.F. Smirnov, V.I. Rimshin, V.L. Kurbatov Biosciences Biotechnology Research Asia. V. 12. No 1. P. 661-669. (2015).

12. A. Krishan, V. Rimshin, S. Markov, V. Erofeev, V. Kurbatov Procedia Engineering 1. P. 211-217. (2015)

13. V.I. Rimshin, E.A. Larionov, V.T. Erofeyev, V.L. Kurbatov Life Science Journal. V. 11. No 11. P. 278-280. (2014)

14. M. Guerin, H. M. Mohamed, B. Benmokrane, A. Nanni, and C. Shield. ACI Structural Journal, Vol. 115, No. 2, pp. 1417-1428. (2018)

15. A. Arafa, and A. Farghaly ACI Structural Journal, Vol. 115, No. 1, pp 211-221. (2018)

16. M. Hassan, A. ElSafty, and A. Fam Journal of Composites Part B: Engineering, Vol. 106, pp. 262-272. (2016)

17. K. Mohamed, F. Farghaly, B. Benmokrane, K. Neale Engineering Structures Journal, Vol. 137, pp. 145-161. (2017) 